\title{
O Lúdico e suas Implicações nas Estratégias de Regulação das Emoções em Crianças Hospitalizadas
}

\author{
Sâmela Soraya Gomes de Oliveira \\ Universidade Federal do Rio Grande do Norte \\ Maria da Graça B. B. Dias ${ }^{1}$ \\ Antonio Roazzi \\ Universidade Federal de Pernambuco
}

\begin{abstract}
Resumo
O estudo procurou verificar se recursos lúdicos modificam as estratégias utilizadas por crianças hospitalizadas em lidar com as emoções de raiva e tristeza. Foram avaliadas 36 crianças de 6 e 10 anos de idade divididas em dois grupos controles (dentro e fora de hospitais) e um grupo experimental (dentro do hospital). Todas foram submetidas a pré e pós testes que avaliaram como as crianças justificavam maneiras de cessar raiva e tristeza em situação de hospitalização. Somente em um dos grupos foi desenvolvida atividade lúdica com sugestões para estratégias mais elaboradas. Os resultados mostram que as estratégias de regulação da emoção (RE) modificavam em função da atividade lúdica; que não houve mudanças em função da idade e do gênero; que a própria testagem por ser considerada uma atividade lúdica, pode possivelmente propiciar mudanças em crianças hospitalizadas.

Palavras-chave: Atividade lúdica; criança hospitalizada; regulação da emoção; sentimento de raiva; sentimento de tristeza.
\end{abstract}

Play and its Implications in the Emotion Regulation Strategies in Hospitalized Children

\begin{abstract}
The present study aimed to investigate if play resources modify the strategies used by hospitalized children to cope with emotions of anger and sadness. Thirty-six 6-and 10-years old children, divided into two control groups, inside and outside the hospital, and one experimental group (inside the hospital), were assessed. They were all submitted to pre and post tests that analysed how these children justified ways to stop feeling angry and sad in a hospitalization situation. In only one of the groups a play activity was developed with suggestions for more elaborated strategies. The results showed that strategies varied according to play activity; that there were no observed variations according to age and gender; that testing itself was considered a play activity and may enable changes in hospitalized children.

Keywords: Playful activity; hospitalized child; regulation of emotion; anger; sadness.
\end{abstract}

Para se falar em regulação da emoção por crianças, se faz necessário discutir sobre o porquê da necessidade do "controle" das emoções por crianças.

Em psicologia, numa perspectiva histórica, o tema "conflito", sempre esteve em pauta. A compreensão da gênese e resolução de conflitos esteve sempre atrelada a uma compreensão maior, relacionada ao desenvolvimento humano e estruturação da personalidade. Autores como Freud (1920, 1929), Erikson (1959/1978), Piaget (1975), Kohlberg (1969) e Vygotsky (1994), mesmo que sob óticas diversas, viram no conflito, e principalmente nos conflitos infantis, a mola propulsora do desenvolvimento de seres humanos.

Freud $(1920,1929)$ deteve-se ao estudo do conflito gerado pela dinâmica da energia libidinal, que investida em

\footnotetext{
${ }^{1}$ Endereço para correspondência: Av. Beira Mar, 520/81, 544000-010, Piedade, Jaboatão, PE. Fone (81) 33612319, Fax (81) 32711843. E-mail: mdias@npd.ufpe.br
}

diferentes regiões do corpo, geraria conflitos no confronto com a realidade, sendo estes conflitos determinantes na estruturação psíquica, no embate Id-Ego-Superego. Para Erikson (1959), o desenvolvimento humano se daria "marcado" por crises chamadas "normativas", ou seja, normais e esperadas, para cada estágio da vida. As crises, também para este autor, seriam essenciais para a seqüência do desenvolvimento. Para as teorias cognitivas-evolutivas como as de Piaget (1975) e Kohlberg (1969), as noções sociais da criança se desenvolvem a partir de sua maturação biológica, mas também em uma interação com meio circundante, que gera conflitos a serem solucionados, a partir dos quais a criança desenvolve suas crenças, atitudes morais em uma reorganização seqüencial utilizando as experiências prévias para novas situações e reorganizandoas. Já em uma perspectiva sócio-historicista, Vygotsky (1994) foi um dos principais articuladores entre psiquê e atividade, tendo sido influenciado pela teoria marxista da sociedade e pelas concepções de Engels sobre trabalho 
humano e o uso de instrumentos como meio para o homem mudar a natureza. Vygotsky estendeu esse conceito da mediação do instrumento para a mudança da natureza externa, para o uso do signo como instrumento mediador para mudar a cultura e o próprio ser humano. Assim como o sistema de instrumentos, os sistemas de signos (a linguagem, a escrita, o sistema de números) são criados pela sociedade e mudam a forma social e consequentemente a própria forma dos seres humanos se posicionarem no mundo; este posicionamento no mundo está também diretamente relacionado com os tipos de conflitos e situações a que os seres humanos são submetidos, próprios de sua sociedade e cultura. Desta forma, para Vygotsky, o mecanismo de mudança individual ao longo do desenvolvimento tem sua raiz na sociedade e na cultura e nos sistemas de signos utilizados para solucionar as situações.

Pode-se observar que, em psicologia, há uma certa tradição em estudar os conflitos infantis dos seres humanos e associá-los ao desenvolvimento desses. Para alguns estudiosos contemporâneos (Dias, Vikan \& Gravas, 2000; Harris, 1996; Harris, Olthof \& Terwogt, 1981; Saarni, 1989; Vikan \& Dias, 1996), analisando a relação conflito em crianças e a forma como estas o solucionam, esta está diretamente ligada a como as crianças regulam suas emoções, utilizando estratégias específicas, próprias de estágios de desenvolvimento, estratégias essas que podem ser determinadas também culturalmente. Entende-se como a regulação da emoção, a modificação intencional, por parte do indivíduo, de uma determinada emoção. Harris (1996) faz uma distinção entre o controle externo da emoção, que inclui comportamentos, gestos, expressões faciais, e o controle da emoção em si.

Harris e colaboradores (1981) investigaram se crianças captam a distinção entre a expressão externa da emoção e a mudança da emoção em si, e se reconhecem que existem estratégias que podem ser utilizadas para mudar estas emoções. Foi verificado que crianças mais velhas (a partir dos 6 anos) começam a explicar cognitivamente as estratégias, ou sugerem estratégias tipicamente cognitivas, relacionadas à mudança no pensamento para que haja uma mudança da emoção. Mesmo quando se referem às mudanças de situação, esta é explicada como sendo eficaz por "distrair".

No entanto, os estudos de Kenealy (1989) e McCoy e Masters (1985) mostram que crianças já de 4 e 5 anos responderam com uma variedade de estratégias, quando lhes foi perguntado sobre o que faziam quando estavam infelizes e o que poderiam fazer para que uma outra criança não sentisse alegria, tristeza ou raiva. Foi verificado um aumento das estratégias verbais e sociais no estudo de McCoy e Masters (1985) e o uso de comportamento reativo ou divertimento no estudo de Kenealy (1989). A avaliação dos resultados se torna difícil pela diversidade de categorias empregadas nos estudos, além da ambigüidade nos testes para detectar as estratégias da Regulação Emocional (RE). Contudo, estes estudos apontam para que crianças menores podem apresentar estratégias para regular suas emoções.

Nas pesquisas de Harris (1996), um outro foco de preocupação foi o de descobrir de que forma as crianças aprendem a usar as distrações para se alegrar e como chegam a perceber os processos mentais que sustentam a emoção. Para o autor, as crianças, através de suas vivências, são capazes de perceber as regularidades causais inerentes à experiência emocional e a partir destas descobertas, tornam-se aptas a mudar intencionalmente seus estados emocionais. Harris (1996) esclarece que esse processo autodidático não se compõe de quaisquer vivências, mas de experiências específicas, salientando duas que cumprem papel instrutivo. A primeira vivência a que o autor se refere, é a de que a emoção é afetada pelos acontecimentos que a sucedem imediatamente. Na investigação desta questão, Harris (1983) utilizando histórias que tratavam da vivência de uma emoção seguida de um acontecimento oposto, aplicadas com crianças de 6 e 10 anos, verificou que tanto crianças mais novas como mais velhas percebiam a relação entre a situação que se sucedia e a mudança da emoção sentida em decorrência desta situação sucessora. Esta percepção, para o autor, parece proporcionar base para a RE, pois dá à criança o entendimento de que sentimentos tristes podem ser minimizados, embora não totalmente abolidos, se sucedidos de uma situação alegre e positiva. Após percebido isso, as crianças podem pôr em prática esta descoberta, no sentido de mudar deliberadamente seu estado anímico.

A outra vivência se refere àquela em que a criança percebe, a partir de suas vivências, que as emoções se dissipam com o passar do tempo e conseguem então, descobrir que a vivência da emoção está relacionada ao fato de se pensar nela, de tê-la em mente. Percebem que o não-pensar auxilia o não-sentir. Harris (1996) cita vários estudos que investigam essa temática (Harris, 1983; Harris, Guz, Lipian \& ManShu, 1985; Taylor \& Harris, 1983). Nesses, as histórias eram contadas às crianças e o personagem central vivenciava uma determinada emoção e se perguntava como ele se sentiria em diversos momentos após a vivência da emoção, até o dia seguinte. Verificou-se que mesmo com quatro anos as crianças já percebem que uma reação emocional se esvai com o tempo. Repetindo o experimento, esses autores identificaram a mesma percepção, o que os levaram a argumentar que o gradual esvaziamento de uma emoção intensa é um universal da experiência humana, e que as crianças desde cedo percebem a existência deste universal.

Pode-se falar então, de um processo linear de compreensão da emoção e da compreensão da utilização 
de estratégias de RE. Aos quatro anos de idade, as crianças já começam a perceber que uma emoção se esvai com o tempo e que isso não acontece somente com elas próprias, mas conseguem projetar isso para outras pessoas e personagens de histórias. Aos 6 anos de idade, já percebem que este desvanecimento da emoção se dá quando não se pensa mais sobre ela e que uma emoção pode ser modificada por uma acontecimento que a sucede. Finalmente, chega um momento em que as crianças passam a entender o princípio da causalidade dos dois fenômenos: a intensidade da emoção se desvanece porque se deixa de pensar sobre ela, seja por causa do tempo decorrido ou pela situação posterior que promoveu uma distração. Esse processo ocorre dos 4 aos 10 anos de idade, período em que as crianças se tornam cada vez mais conscientes deste conexo causal. Estas descobertas, por sua vez, vão proporcionar à criança uma habilidade em utilizar deliberadamente estratégias de RE.

A partir dos estudos anteriores, poder-se-ia concluir que a conceituação que a criança faz da emoção é em grande parte determinada por sua idade e pela correspondente capacidade cognitiva. Contudo, outros estudos apontam que esta idéia não é de todo sustentável.

Uma problemática quanto à temática da RE, ressaltada no estudo de Vikan e Dias (1996) e Dias, Vikan e Gravas (2000), é a questão do contexto e a sua relação com a utilização de estratégias. Os autores citam os estudos nos quais o contexto tem sido observado como influenciando estratégias emocionais (Altshuler \& Ruble, 1989; Band \& Weisz, 1988; McCoy \& Masters, 1985). Apontam também, outros estudos cujos resultados mostram que o controle do contexto parece determinar a escolha em lidar com um problema ou com uma determinada emoção (Altshuler \& Ruble, 1989). Vikan e Dias (1996) e Dias e colaboradores (2000) salientam que variações relacionadas ao tipo de emoção podem ser consideradas erroneamente como sendo variações do contexto, quando este último não está especificado. A partir de estudos com crianças norueguesas e brasileiras em que o objetivo foi verificar o uso de estratégias em crianças, sua mudança em relação à idade que pudesse indicar um desenvolvimento neste uso e as contribuições do tipo de emoção e contexto na variação de estratégias, foi verificado que a grande maioria das crianças de 4 e 5 anos poderia propor estratégias de RE para tristeza e raiva e que o contexto foi a maior fonte de variação para as respostas sobre duração da emoção e apoio social. Foi verificada uma diferença significativa na freqüência de uso de determinadas estratégias entre as crianças brasileiras e norueguesas. Enquanto as crianças brasileiras enfocam mais como estratégia de RE, a brincadeira e a interação social, as norueguesas focalizam mais o comportamento da pessoa em relação a si mesma (Ex.: construir algo) e nas estratégias de RE por regras morais (Ex.: altruísmo). Os autores ressaltam que:

Estes resultados podem sugerir que a vida emocional é guiada de diferentes maneiras, ou nos termos de Hochschild (1979), regras de sentimentos são aplicadas em uma extensão diferente para as diferentes emoções dentro das duas culturas. Realçar estas diferenças pode resultar em estereótipos culturais: as crianças brasileiras regulam suas emoções através de atividades alegres e do grupo social, e concentram o pensamento nas próprias emoções. Já as norueguesas regulam suas emoções pela moral, pelo que acontece ao corpo, aos pertences e/ou às produções do indivíduo, e concentram o pensamento na evitação e/ou intelectualização das emoções. Em outras palavras, as brasileiras são alegres, sociais e emocionais; enquanto as norueguesas são sérias, solítárias e racionais. (Vikan \& Dias, 1996, p. 41)

Diante das idéias expostas, algumas considerações se fazem necessárias em se tratando de crianças hospitalizadas. Ao nos depararmos com indicadores que apontam para uma tendência das crianças brasileiras em utilizar com mais freqüência as estratégias de RE que envolvem interação social e brincadeiras, como seriam utilizadas estas estratégias no ambiente hospitalar? O contexto da hospitalização influenciaria na compreensão e uso das estratégias de RE?

Harris e Lipian (1989), em seus estudos com crianças hospitalizadas e saudáveis, de 6 e 10 anos, compararam estes dois grupos em que as variáveis nível socioeconômico e intelectual foram controladas a fim de verificar se existiam diferenças significativas, na compreensão das emoções e na utilização de estratégias de RE entre estes dois grupos. Às crianças saudáveis, pedia-se que lembrassem da última vez em que estiveram doentes para responder as questões; as crianças doentes responderiam a partir da vivência da experiência imediata.

Entre as crianças sadias, verificou-se uma mudança em função da idade, como nos outros experimentos. As crianças de 6 anos, em sua maioria, achavam que nada poderia ser feito, mas entre as crianças de 10 anos, quase todas recomendavam a estratégia de distração, ou a utilização de brinquedos ou jogos em uma atividade agradável. Já entre as crianças hospitalizadas, essas diferenças praticamente desapareceram; mais da metade das crianças de 6 e 10 anos, foram pessimistas e acharam que nada poderia ser feito para mudar a situação. Esta conclusão não foi alterada, nem mesmo com a insistência do entrevistador.

Entre as crianças hospitalizadas que admitiram ser possível a mudança de um sentimento para outro, verificouse que, ao pedir-lhes para explicar como isso poderia ser feito, essas seguiram a costumeira mudança em função da 
idade apresentada em outros estudos. As crianças de 6 anos recorreram às atividades associadas à emoção positiva e o uso de jogos e brinquedos, justificando poucas vezes suas propostas com explicações cognitivas. Algumas de 10 anos também propuseram esta atividade sem uma explicação cognitiva, mas com igual freqüência outras da mesma idade referiram-se a uma atividade agradável e explicaram o seu efeito de distração. Harris afirma ainda que:

Apesar dessa similaridade geral quanto ao conteúdo das estratégias, as crianças hospitalizadas são mais pessimistas com respeito a tais estratégias que crianças sadias. Tendem muito a rejeitar a opinião de ser possível alegrar-se. A diferença costumeira entre crianças de 6 a 10 anos é parcialmente eliminada entre as crianças hospitalizadas, porque as crianças mais velhas muitas vezes chegam a conclusões características de crianças mais novas. (Harris, 1996, p. 175)

Embora não se possa determinar com exatidão o que necessariamente causa esta diferença na concepção da emoção em crianças hospitalizadas e a maneira diversa de lidar com estratégias de RE, alguns pontos podem ser discutidos: o que falta no ambiente hospitalar para que essas crianças se percebam capazes de enfrentar a situação de hospitalização e de alguma forma mudar o seu estado anímico? O fato da equipe hospitalar exigir das crianças um comportamento "calmo, quieto e obediente" para melhor manipulá-las não "exigiria" delas uma forma de utilizar estratégias de RE a que não estão habitualmente acostumadas (Ex.: racionalização e moralidade)? Existem formas destas crianças utilizarem a interação social e a brincadeira como formas de estratégias de RE?

Atualmente, muitos estudos são dedicados à compreensão do instrumento lúdico como potencializador do desenvolvimento. Desde o brinquedo utilizado nas préescolas em ludotecas, até como instrumento clínico, em consultórios, o brinquedo tem sido amplamente utilizado, abrindo espaços para discussão e estudos que procuram apontar como este instrumento, típico da fase da infância, pode se configurar em um objeto de estudo bastante rico.

Para alguns autores (Bruner, 1976, 1978; Langley, 1985; Rubin \& Howe, 1985; Vieira, 1994; Vygotsky, 1994; Winnicott, 1978), o brinquedo é, indiscutivelmente, um veículo que media a relação da criança com o mundo e influencia na maneira de como as crianças se relacionam e interagem.

Para Vygotsky (1994), o prazer não pode ser considerado a característica definidora do brinquedo, como muitos pensam. Para o autor, o brinquedo na verdade, preenche necessidades, entendendo-se estas necessidades como motivos que impelem a criança à ação. São exatamente estas necessidades que fazem a criança avançar em seu desenvolvimento.

Para Bruner (1976,1978), o jogo, ao ocorrer em situações sem pressão, em atmosfera de familiaridade, segurança emocional e ausência de tensão ou perigo, proporciona condições para a aprendizagem das normas sociais em menor risco. A conduta lúdica oferece oportunidades para experimentar comportamentos que, em situações normais, jamais seriam tentados por medo de erro ou punição.

Ao brincar interativamente com os adultos, a criança começa a alterar o curso da brincadeira pelo prazer que dela emana, desenvolvendo então a competência de recriar situações, em uma conduta criativa. Tais brincadeiras contribuem para o desenvolvimento cognitivo. Brincando, a criança vai além da situação na busca por soluções, pela ausência de avaliação ou punição. Bruner (1978) entende que a criança aprende a solucionar problemas e que o brincar contribui para esse processo.

Langley (1985) verificou que brinquedos adequados manipulados por crianças com limitações cognitivas podem contribuir para um melhor desenvolvimento das mesmas. Mas quando se fala de limitações, um déficit no sentir pode ser também considerado uma limitação cognitiva? Harris e Lipian (1989) apontaram uma perda na capacidade de compreender estratégias de RE em crianças hospitalizadas quando comparadas às crianças saudáveis. Isso pode se configurar em uma perda de capacidade cognitiva provavelmente gerada pela situação de hospitalização.

Atualmente, a problemática das questões ligadas às instituições hospitalares no Brasil é indiscutivelmente de proporções gigantescas e muitas questões aparecem quando o assunto é a Saúde Pública; questões elementares, desde oferecer serviços básicos de saúde à população em geral, até questões mais complexas, que colocam em xeque a própria prática médica e as noções de saúde e doença. Problemas ligados à falta de estrutura básica de atendimento, de recursos para a aquisição de materiais imprescindíveis, como medicamentos, por exemplo, são infelizmente, mais norma que exceção, dentro da panorâmica caótica de saúde no país. Entretanto, o presente trabalho traz à tona uma problemática existente até mesmo nas instituições privadas, em que se excluem os problemas financeiros, a falta de materiais e profissionais insatisfeitos pela inexistência de estrutura para trabalhar; fala-se da desumanização no atendimento, principalmente à criança, problema encontrado em instituições de regiões desenvolvidas e subdesenvolvidas, o que aponta para problemas não de ordem estrutural, mas de ordem paradigmática, existente no próprio conceito de atendimento à saúde (Chiattone, 1988). 
Ao se deparar com a situação de hospitalização, a criança em geral se vê assustada, principalmente pelo ambiente hostil da instituição hospitalar. Paredes lisas, sem estimulação; pessoas enfermas deitadas em seus leitos e outras desconhecidas que circulam de lá para cá que impõem o cumprimento de regras e bom-comportamento; a manipulação do corpo de forma invasiva e dolorosa; a perda de autonomia, pois as regras são determinadas pela equipe de saúde e a separação do ambiente familiar reconhecido. Esse é o quadro normal com que a criança internada se depara nas instituições hospitalares, o que faz com que o hospital se transforme em um ambiente hostil para a grande maioria das crianças (Campos, 1995; Chiattone, 1988, 1996; Latham, Heckel, Hebert \& Bennett, 1977; Lindquist, 1993; Maldonado, 1989).

Este ambiente asséptico é em geral aterrorizante, pois não há nada nele que a criança possa identificar com suas experiências anteriores; somado a isso, o fato de sua debilitação física e emocional estarem presentes na situação a tornam ainda mais agravante.

A equipe hospitalar, por sua vez, preocupa-se muito mais com a "restauração do órgão debilitado", que com a saúde da criança, não levando em conta o seu desenvolvimento cognitivo e emocional para compreendê-la e auxiliá-la no enfrentamento da situação.

Chiattone (1988) aponta para vários distúrbios conseqüentes da hospitalização, que muitas vezes estão associados à impossibilidade da criança em lidar com os acontecimentos. Entre esses distúrbios, pode-se salientar culpa e depressão, angústia, personalidade instável, falta de iniciativa, diminuição na vocalização, atraso no desenvolvimento cognitivo e emocional, agressividade e manifestações psicossomáticas.

Muitos autores, dentre eles Chiattone (1988, 1996), Maldonado (1989), Mello Filho (1992), Campos (1995), chamam atenção para os aspectos psicológicos que podem influenciar na evolução do quadro clínico do paciente, agravando-o, pelo aumento do nível de stress.

Que tipo de recursos poderia dispor um hospital para favorecer às crianças a compreensão e utilização de estratégias de RE, se encontrados indícios de que as crianças brasileiras hospitalizadas, assim como no estudo de Harris e Lipian (1989), não apresentam mudanças significativas em função da idade e denotam, segundo os autores, um pessimismo que as leva a crer que não há nada que se possa fazer para mudar uma emoção?

O presente estudo procurou fazer uso do brinquedo dirigido, com tarefas lúdicas estruturadas, utilizado em poucos hospitais pediátricos de forma sistemática, para verificar se existe uma correlação significativa entre o seu uso e a mudança na compreensão e utilização das estratégias de RE entre crianças.

No âmbito da situação hospitalar, tem-se o brinquedo como principal recurso para a preparação de crianças para as diversas situações que podem ocorrer, como apontam Chiattone (1988) e Lindquist (1993). Elaborar essas situações derivadas da hospitalização significa conceituá-las, dar significações, construir estratégias de RE para adaptar-se, entrar em contato com os sentimentos negativos e positivos relacionados à nova situação e posicionar-se em relação a eles, entre outros processos que deverão ser desenvolvidos cognitiva e emocionalmente. Como foi visto, o brinquedo atende às duas instâncias (cognitiva e emocional) que se pretende trabalhar no hospital. A aplicação de recursos lúdicos transforma-se em um potencializador no processo de recuperação da capacidade de adaptação da criança hospitalizada, diante de transformações que se darão a partir de sua entrada no hospital.

O brinquedo, no hospital, assume o significado de instrumento, com funções específicas e formas próprias de aplicabilidade. Chiattone (1988), em seus trabalhos com crianças hospitalizadas, divide os tipos de brinquedos em duas categorias, o brinquedo livre e o brinquedo dirigido.

As atividades com o brinquedo livre são desenvolvidas com todos os materiais que se encontram disponíveis, com atividades que são desenvolvidas pela criança, mas orientadas e observadas por um coordenador. As crianças se posicionam dentro das brincadeiras diante de determinados assuntos que são orientados por um coordenador quanto à elaboração das questões que emergirem.

Chiattone (1988, p. 99) se refere ao brinquedo livre, enfatizando:

Apesar do aspecto livre da atividade, as crianças não brincam por brincar, na medida que durante todo o período procuramos conversar, orientar e apoiá-las da melhor maneira possível. O próprio brinquedo nos mostra o caminho escolhido pela criança e pelo qual devemos adentrar e trabalhar os conteúdos existentes.

As atividades com o brinquedo dirigido são previamente estruturadas e dizem respeito ao trabalho com temas específicos, relacionados a uma problemática que pode ser individual ou de um grupo de crianças. Estas atividades têm por objetivo facilitar a elaboração de sentimentos em relação a uma determinada questão e elaborar estratégias de enfrentamento. A manipulação do material está diretamente ligada ao momento da vida das crianças e facilita a verbalização dos sentimentos encobertos. No caso específico da aplicação de técnicas lúdicas em hospitais, os 
brinquedos abordam temas hospitalares, podendo-se citar: bonecos que representam a família, o paciente e a equipe hospitalar; bonecos que deixam à mostra os órgãos internos; instrumentos cirúrgicos, de exames e de procedimentos médicos em miniaturas de plástico; maquetes de hospitais e enfermarias; carrinhos de ambulância; roupas idênticas às da equipe; materiais utilizados pela equipe de enfermagem; livros de histórias em que o tema esteja ligado ao período de hospitalização ou processo de saúde-doença. Chiattone (1988, p. 97) argumenta que:

Em contato com esse material, as crianças estabelecem situações, cirurgias, condutas terapêuticas, exames físicos, morte de pacientes, atendimentos de urgência, enfim, toda uma série de situações que vivenciam ou imaginam e que necessitam elaborar. A oportunidade que se dá através dessa atividade é a colocação direta de sentimentos específicos com a ajuda de material lúdico.

Diante dos argumentos expostos nesses estudos, observa-se a necessidade de se encontrar formas de auxiliar a criança na construção ou compreensão de elaborar técnicas de RE, tendo em vista que o período de hospitalização é de difícil compreensão para as crianças, sobretudo as mais novas. Que estratégias de RE utilizam essas crianças para o medo e a raiva - dois sentimentos associados ao período de hospitalização? Os recursos lúdicos aplicados nas enfermarias pediátricas têm realmente uma correlação com a elaboração desta estratégias? À investigação desta pergunta se deterá o presente trabalho; o brinquedo no hospital é realmente um instrumento eficaz para que crianças doentes regulem os sentimentos de raiva e tristeza?

\section{Método}

\section{Participantes}

Grupo Controle 1: Fizeram parte do Grupo Controle 1 (GC1), 12 crianças em situação de hospitalização, devido a distúrbios orgânicos com bom prognóstico, sem graves comprometimentos e risco de vida. Seis dessas crianças estavam com 6 anos completos, sendo 3 do sexo masculino e 3 do sexo feminino e 6 delas estavam com 10 anos completos, sendo 3 do sexo masculino e 3 do sexo feminino.

Grupo Controle 2: Fizeram parte do Grupo Controle 2 (GC2), 12 crianças consideradas sadias que já tinham estado em situação de hospitalização devido a distúrbios orgânicos com bom prognóstico, mas que se encontravam em bom estado de saúde no momento e fora do ambiente hospitalar. Seis dessas crianças estavam com 6 anos completos sendo 3 do sexo masculino e 3 do sexo feminino e 6 delas estavam com 10 anos completos, sendo 3 do sexo masculino e 3 do sexo feminino.

Grupo Experimental: Fizeram parte do Grupo Experimental (GE), 12 crianças em situação de hospitalização, devido a distúrbios orgânicos com bom prognóstico, sem graves comprometimentos e risco de vida. Seis dessas crianças estavam com 6 anos completos, sendo 3 do sexo masculino e 3 do sexo feminino e 6 delas estavam com 10 anos completos, sendo 3 do sexo masculino e 3 do sexo feminino.

Assim, 12 crianças estavam internadas nas enfermarias do Hospital de Pediatria da Universidade Federal do Rio Grande do Norte e 12 crianças no Hospital Infantil Varela Santiago, ambos hospitais que servem à população de Natal, Rio Grande do Norte. O fato de terem sido coletados dados em diferentes hospitais deveu-se ao fato de evitar-se qualquer tipo de influência devido aos procedimentos relativos à coleta do GC2 e do GE, já que muitas vezes a coleta de dados foi feita na própria enfermaria, no leito da criança; o contato entre essas crianças poderia se tornar uma variável difícil de controle.

Foram controladas as variáveis escolaridade, nível socioeconômico e gênero, que foram os mesmos nos 3 grupos.

\section{Material e Procedimento}

Foram utilizadas duas pequenas histórias com perguntas posteriores (Anexos $\mathrm{A}^{1}, \mathrm{~A}^{2}, \mathrm{~B}^{1}, \mathrm{~B}^{2}$ ), para a avaliação do nível de compreensão das estratégias de RE e da utilização dessas por estas crianças, que foram aplicadas em um préteste (Anexos $\mathrm{A}^{1}, \mathrm{~A}^{2}$ ) e em um pós-teste (Anexos B ${ }^{1}, \mathrm{~B}^{2}$ ). Estas historinhas foram elaboradas para que se pudesse avaliar a compreensão das crianças sobre as estratégias de RE e possíveis alterações nos dois momentos: antes e depois da aplicação da tarefa lúdica (Anexo C) no grupo experimental, e algum tipo de alteração mesmo sem a aplicação desta tarefa nos grupos controle 1 e 2 .

A tarefa lúdica (Anexo C) consistiu em uma brincadeira com o mesmo tipo de roteiro das historinhas aplicadas, mas que deixaram para a criança a função de finalizá-lo. $\mathrm{O}$ experimentador deveria intervir na brincadeira a fim de criar a situação que eliciasse um momento de raiva e tristeza e apontar direções para solução através da utilização das estratégias de RE estudadas. Essas brincadeiras tiveram dois temas gerais: a) uma criança hospitalizada (do mesmo gênero da criança) e o sentimento de raiva em decorrência da hospitalização; e b) uma criança hospitalizada (do mesmo gênero da criança) e o sentimento de tristeza em decorrência da hospitalização.

Os brinquedos utilizados consistiram da família de fantoches, com bonecos que representaram as figuras principais, Pai, 
Mãe, Criança 1 e Criança 2, Avô e Avó; equipe médica de fantoches que representaram o Médico, Médica, Enfermeiro e Enfermeira.

\section{Procedimento}

O experimentador iniciou seus trabalhos aplicando a historinha do pré-teste com o seu respectivo questionário nos três grupos de crianças, (ver Anexo $\mathrm{A}^{1}, \mathrm{~A}^{2}$ ) identificando qual a compreensão do uso de estratégias de RE nas crianças e quais as estratégias utilizadas por elas. Em um segundo momento, no dia seguinte, somente o GE foi submetido à aplicação dos recursos lúdicos (ver Anexo 3). Finalmente, no $3^{\circ}$ dia do procedimento, os três grupos foram submetidos ao pós-teste, para verificar se houve mudanças no período decorrido (ver Anexos 2 a e 2 b). O procedimento total foi desenvolvido em 3 dias, um dia para cada etapa: pré-teste, experimento (só para o grupo experimental) e pós-teste. Nos grupos controle, no dia em que seria desenvolvido o experimento, não foi feita nenhuma atividade, para que se pudesse controlar a variável tempo decorrido em todos os grupos. O fato de a coleta ter sido realizada em um curto período de tempo deu-se principalmente porque muitas crianças têm alta hospitalar em 4 ou 5 dias, e desta forma, se o estudo houvesse sido estruturado em um período mais longo, comprometeria a testagem posterior.

Para que não se pudesse ter viéses em função do contato de crianças do GC1 com crianças do GE, os dados foram coletados em hospitais distintos para os dois grupos. Em um, o Hospital Infantil Varela Santiago somente crianças do GC1 foram entrevistadas e reentrevistadas; em um outro, o Hospital de Pediatria da Universidade Federal do Rio Grande do Norte, os dados do GE foram coletados.

A preocupação em haver dois grupos controle foi devido a possíveis alterações que poderiam ser atribuídas à situação. Observando as diferenças entre os GE e GC1 e os GE e GC2, poderíamos obter dados relevantes sobre as diferenças encontradas quando se muda o ambiente (GE x GC1) e aquelas que não dependem do ambiente (GE x GC2), devendo ser atribuídas, então, à tarefa lúdica.

\section{Resultados}

As justificativas das crianças foram inseridas em 11 Categorias, adaptadas do estudo de Vikan e Dias (1996) que vão das menos elaboradas para as mais elaboradas, com a compreensão das técnicas cognitivas utilizadas deliberadamente para a mudança da emoção (ver Tabela 1).
Tabela 1

Categorias de Justificativas Dadas pelas Crianças

\begin{tabular}{ll}
\hline 1 & Não Sei \\
2 & Nada Pode Ser Feito \\
3 & Mudança de Ambiente \\
4 & Brincar \\
5 & Interação Social \\
6 & Agir com Violência \\
7 & Altruísmo \\
8 & Procurar Ajuda de Alguém Mais Velho \\
9 & Ajustamentos Emocionais \\
10 & Estímulos Focados \\
11 & Técnicas Cognitivas \\
\hline
\end{tabular}

As categorias foram ordenadas respeitando as justificativas dadas pelas crianças quanto à escolha das estratégias, se essas eram sucedidas de justificativas menos ou mais cognitivas. De uma forma geral, as justificativas das categorias se reportavam de um grau menor a um maior do pensamento, desde a categoria "Não Sei" até a "Técnicas Cognitivas". Três juizes independentes classificaram as justificativas obtendo $100 \%$ de acordo. As respostas só foram consideradas nas categorias 1 e 2 quando, mesmo com insistência do examinador, não havia reformulação de resposta, demonstrando que era realmente esse o posicionamento da criança.

Foram consideradas na categoria Mudança de Ambiente, as respostas que se reportavam a mudar o ambiente ou o contexto da situação, por exemplo: voltar para casa, mudar de quarto, passear em outro lugar. $\mathrm{Na}$ categoria Brincar, foram consideradas as respostas que se relacionavam às atividades de brincadeira, como jogar, brincar, brincar com brinquedos. Na categoria Interação Social, foram consideradas as respostas dadas referentes a atividades em grupos ou com pessoas específicas, como por exemplo brincar com amigos, ver os amigos, conversar com os pais, receber visitas. Na categoria Agir com Violência, foram consideradas as respostas que se referiam a comportamentos agressivos dirigidos a alguém, como por exemplo bater em uma criança, xingar alguém, dizer palavrões. $\mathrm{Na}$ categoria Altruísmo, foram consideradas as respostas que se referiam a atitudes complacentes, de ajuda, como por exemplo conversar para ajudar, ajudar, ser compreensivo. Na categoria Procurar Ajuda de Alguém Mais Velho, foram consideradas as respostas que se referiam a atitudes de chamar alguém para ajudar a resolver a situação, como por exemplo chamar a mãe, chamar o pai, chamar o médico, chamar a enfermeira. Na categoria Ajustamentos Emocionais, foram consideradas as respostas que se 
reportavam a tentativas de modificar diretamente uma emoção, como por exemplo, não levar a sério, ficar calmo, tentar se acostumar. Na categoria Estímulos Focados, foram consideradas as respostas dadas que se referiam a atitudes de focalizar em um estímulo para modificar uma emoção, como por exemplo, pensar em outra coisa, pensar na volta para casa, pensar nos amigos. Na categoria Técnicas Cognitivas, foram consideradas as respostas dadas referentes às formas de maior racionalização no emprego de estratégias para controle da emoção, como por exemplo, pensar que aquilo não significa nada, parar de pensar na situação, dizer para si mesmo que aquilo não significa nada, esquecer a situação.

Na Tabela 2 encontram-se as médias das categorias de respostas tanto no Pré como no Pós-Teste, levando em consideração o grupo (Controle 1, Controle 2 e Experimental) e a Idade (6 e 10 anos). Pode-se notar que tanto no Grupo de Controle 1 como no Grupo de Controle 2 , as diferenças entre as categorias de respostas entre Pré e
Pós-Teste são pequenas, independentemente da emoção como da faixa etária. Já no Grupo Experimental, as categorias utilizadas pelas crianças no Pós-Teste foram muito mais elaboradas do que no Pré-Teste.

As diferenças entre o Pré e Pós-Teste foram analisadas através de Análise de Variância não-paramétrico para amostras emparelhadas (teste de Friedman). Este teste demonstra não existirem diferenças significativas entre o PréTeste e o Pós-Teste nos dois grupos de Controle (1 e 2) tanto para a emoção Cessar Raiva como para a emoção Cessar Tristeza. Já as crianças do Grupo Experimental demonstram um nível significativamente mais elaborado de justificativas no Pós-Teste quando comparado ao PréTeste tanto para a emoção Cessar Raiva como para a emoção Cessar Tristeza. Estas diferenças nas médias de justificativas de respostas podem ser visualizadas nas Figuras 1 e 2. Enfim, como pode-se observar, praticamente houve ausência de mudanças nos grupos controle, enquanto que as crianças do Grupo Experimental, após submetidas ao

Tabela 2

Média das Categorias de Respostas em "Cessar Raiva” e "Cessar Tristeza” no Pré-Teste e no Pós-Teste em Função do Grupo e da Idade e $\chi^{2}$ do Teste de Friedman

\begin{tabular}{|c|c|c|c|c|c|c|c|c|c|c|c|c|}
\hline \multirow{2}{*}{$\begin{array}{r}\text { Emoção/ } \\
\text { Idade }\end{array}$} & \multicolumn{4}{|c|}{ Controle 1} & \multicolumn{4}{|c|}{ Controle 2} & \multicolumn{4}{|c|}{ Experimental } \\
\hline & Pré & Pós & Dif. & $\chi^{2}$ & Pré & Pós & Dif. & $\chi^{2}$ & Pré & Pós & Dif. & $\chi^{2}$ \\
\hline \multicolumn{13}{|l|}{ Cessar Raiva } \\
\hline 6 anos & 3,5 & 5,0 & 1,5 & 2 & 5,8 & 5,5 & 0,3 & 2 & 4,3 & 9,7 & 5,4 & $5^{*}$ \\
\hline 10 anos & 4,7 & 5,2 & 0,5 & 1 & 8,0 & 9,0 & 1,0 & 2 & 6,0 & 10,2 & 4,2 & $6^{*}$ \\
\hline Total & 4,1 & 5,1 & 1,0 & 2 & 6,9 & 7,2 & 0,3 & 0,0 & 5,1 & 9,9 & 4,8 & $11 * * *$ \\
\hline \multicolumn{13}{|l|}{ Cessar Tristeza } \\
\hline 6 anos & 3,2 & 3,0 & $-0,2$ & 1 & 3,7 & 4,0 & 0,3 & 1 & 3,0 & 7,2 & 4,2 & $4 *$ \\
\hline 10 anos & 3,3 & 3,3 & 0 & 0 & 4,3 & 4,0 & $-0,3$ & 2 & 3,0 & 7,5 & 4,5 & $5^{*}$ \\
\hline Total & 3,2 & 3,1 & $-0,01$ & 0,33 & 4,0 & 4,0 & 0 & 0,33 & 3,0 & 7,3 & 4,3 & $9 * *$ \\
\hline
\end{tabular}

Nota . Dif. = Diferença entre Pós-Teste e Pré-Teste; Pré = Pré-Teste; Pós = Pós-Teste. $\quad *=p<0,05 ; * *=p<0,01 ; * * *=p<0,001$

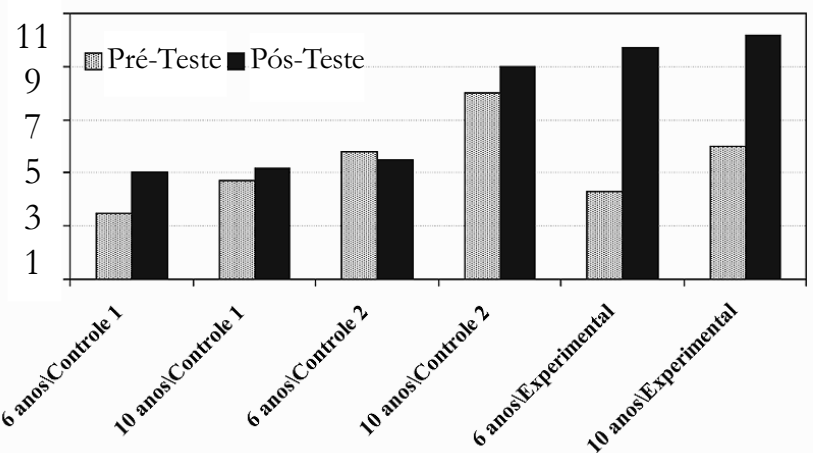

Figura 1. Médias das categorias de respostas em Cessar Raiva no pré- e pós-teste em função do grupo e da idade.

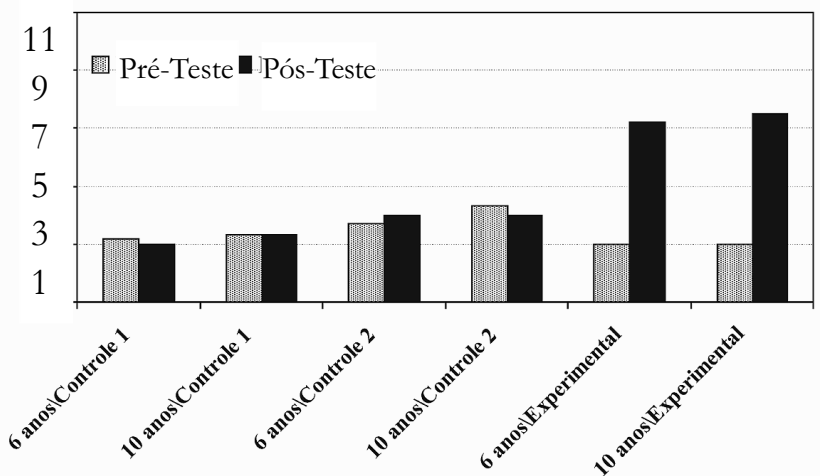

Figura 2. Médias das categorias de respostas em Cessar Tristeza no pré no e pós-teste em função do grupo e da idade. 
experimento lúdico, demonstraram mudanças bastante significativas.

Em seguida, visando avaliar a estrutura relacional das emoções Cessar Raiva e Cessar Tristeza tanto no Pré-Teste como no Pós-Teste, foi realizada uma análise multidimensional denominada Análise da Estrutura de Similaridade (Similarity Structure Analysis SSA - Borg \& Lingoes, 1987, anteriormente denominada também de Smallest Space Analysis - Bayley, 1974; Guttman, 1965), que faz parte da série de programas não-métricos 'GuttmanLingoes' que se fundamenta no trabalho de Louis Guttman (Lingoes, 1968; para maiores detalhes ver Roazzi, 1995). Mais especificamente, esta análise processa uma matriz de correlação entre $n$ variáveis através de representações gráficas destas variáveis como pontos em um espaço Euclidiano chamados "menores espaços". Pontos representando as variáveis são projetados num espaço, de modo que quanto maior for a correlação entre duas variáveis, mais próximas elas se localizarão no espaço da projeção e vice-versa, criando-se, assim 'regiões de contiguidade' ou 'regiões de descontinuidade' representando espacialmente as correlações entre-itens. As hipóteses iniciais são assim transformadas em hipóteses regionais, visto que se objetiva encontrar regiões de itens na configuração-SSA que correspondem aos elementos das facetas consideradas. Se para uma faceta, um conjunto de regiões não é observado, então não existe evidência empírica por aquela faceta. É possível, assim, descobrir a estrutura latente que emana dos dados através de uma representação espacial facilmente compreensível ao ser indagada de forma visual. Isto é, constrói-se uma representação geométrica dos dados, usualmente em um espaço Euclidiano, de dimensionalidade mínima capaz de retratar de forma fiel a relação entre todas as relações das variáveis investigadas. O que é importante no SSA é a divisão do espaço da projeção em regiões. Como afirma Young (1987) “o elemento essencial de definição de todo método de escalonamento multidimensional, é a representação espacial da estrutura de dados" (p. 3). Os procedimentos do SSA diferem de outros métodos clássicos de MDS pela forma de obtenção da transformação monotônica. No lugar de usar a transformação do quadrado mínimo, o SSA classifica as distâncias dentro da ordem especificada a partir dos próprios dados (Guttman 1968; Young, 1987) não impondo ortogonalidade nos dados como ocorre na análise fatorial.

A "técnica das variáveis externas como pontos" foi utilizada para verificar a relação da variável grupo (Experimental, Controle 1 e 2) com a estrutura relacional das emoções Cessar Raiva e Cessar Tristeza no Pré-Teste e Pós-Teste. Esta técnica possibilita integrar sub-populações nos mapas MDS, i.e., possibilita localizar espacialmente variáveis externas (as duas séries) como pontos na estrutura interna representada na projeção SSA que permanece inalterada. Assim, no lugar de analisar diferentes mapas SSA, um por cada subgrupo, é produzido um único mapa integrado representando ao mesmo tempo a estrutura das histórias e os dois subgrupos (as duas séries escolares).

Após produzir o mapa SSA, representando as correlações entre as duas emoções Raiva e Tristeza nas fases de Pré-Teste e Pós-Teste (variáveis conteúdos), os três grupos - Experimental, Controle 1 e 2, eram introduzidos no mesmo mapa. Em outras palavras, após ter produzido um mapa representando as correlações entre as variáveis conteúdos, três variáveis externas (variáveis background) eram localizadas no mesmo mapa sem que fosse modificada a localização das variáveis conteúdos originais. Esta independência entre os dois grupos de variáveis é fundamental, visto que teoricamente as variáveis externas de maneira alguma podem afetar a posição das variáveis conteúdo.

Para gerar um único mapa integrado capaz de representar todos os dados (variáveis de conteúdo e externas) foram criadas as duas variáveis dummy a partir da variável grupo. A variável grupo apresentava três categorias, cada uma correspondendo a um grupo específico - 1 para o grupo de Controle 1 e o grupo de 2 para Controle 2 e 3 para o grupo Experimental. A partir desta única variável, construímos três variáveis dicotômicas denominadas variáveis dummy. Assim, a variável Controle 1 é uma cópia da variável original grupo, na qual a categoria 1 (Controle 1) permanece com a categoria 1 ( $\operatorname{sim})$ e as categorias 2 (Controle 2) e 3 (Experimental) são modificadas para 0 (não). De forma similar, a variável Controle 2 é uma cópia da variável original grupo na qual a categoria 2 (Controle 2 ) é modificada para a categoria $1(\mathrm{sim})$ e as categorias 1 (Controle 1) e 3 (Experimental) são modificadas para 0 (não). Enfim, a variável Experimental é uma cópia da variável original grupo na qual a categoria 3 (Experimental) é modificada para a categoria $1(\mathrm{sim})$ e as categorias 1 (Controle 1) e 2 (Controle 2) são modificadas para 0 (não). A escolha desta direção (1 para "sim" e 0 para "não") é congruente com a ordem das justificativas das crianças categorizadas em 11 níveis que vão das menos elaboradas para as mais elaboradas. O princípio geral para ser utilizado é que a variável externa precisa ser construída na mesma direção da variável interna de conteúdo. De regra, "sim" na variável externa dummy corresponde a um alto valor na variável de conteúdo. Assim, se as variáveis internas ou de conteúdo aumentam (de negativo para positivo: maior compreensão das técnicas cognitivas utilizadas deliberadamente para a mudança da emoção), as variáveis externas precisam aumentar no mesmo sentido (para maiores detalhes sobre a validação desta 
Tabela 3

Matriz de Correlação (Coeficiente de Monoticidade) entre as duas Emoções Raiva e Tristez̧a em cada Fase (Pré-Teste e Pós-Teste)

\begin{tabular}{lcccc}
\hline Fase/Emoção & Pré-Teste/ Raiva & Pós-Teste/ Raiva & Pré-Teste/ Tristeza & Pós-Teste/ Tristeza \\
Pré-Teste/Raiva & 100 & 100 & & \\
Pós-Teste/Raiva & 89 & 56 & 100 & 100 \\
Pré-Teste/Tristeza & 68 & 92 & 9 & 100 \\
Pós-Teste/Tristeza & 48 & &
\end{tabular}

Nota. Os coeficientes originais foram multiplicados por 100 e os valores arredondados

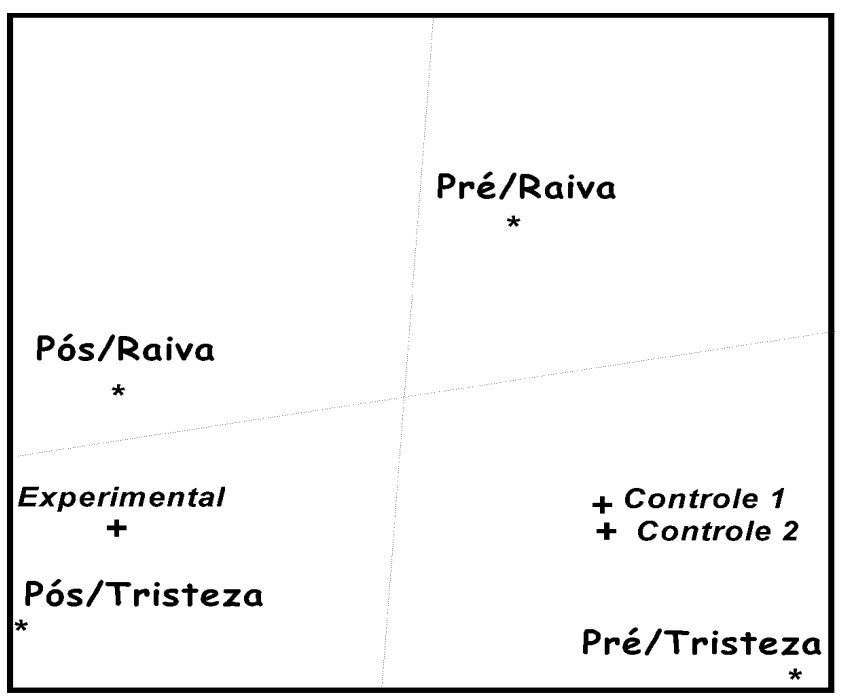

Coordenada 1 versus 2 da análise bidimensional

Figura 3. Projeção da análise de estrutura de similaridade (ssa) das fases de pré-teste e pós-teste por cada emoção considerando como variáveis externas os 3 grupos (controle 1, controle 2 e experimental). (coeficiente de alienação: 0,000)

técnica ver Amar \& Levy, 1995; Cohen \& Amar, 1999; Lyra, Roazzi \& Cohen, 2001).

$\mathrm{Na}$ Tabela 3, é apresentada a matriz de correlação (Weak Monotonicity Coefficient-MONCO) das fases de PréTeste e Pós-Teste de cada emoção. A projeção que resulta desta análise é apresentada na Figura 3. É necessário interpretar a projeção em dois momentos. É preciso antes analisar a configuração espacial das variáveis conteúdos e verificar a existência das duas facetas planejada no estudo: fase de avaliação (Pré-Teste e Pós-Teste) e tipo de emoção (Raiva e Tristeza). Em seguida, é preciso analisar como as variáveis externas se localizam na configuração do espaço SSA formado pelas variáveis de conteúdo, visto que a localização destas variáveis externas nos indicará o efeito da intervenção.

A partir de uma inspeção da projeção considerando somente as variáveis conteúdo observa-se que é possível a projeção de forma axial de acordo com das duas facetas fase e emoção. Observa-se também que as duas emoções na fase de Pós-Teste se localizam mais próximas entre si do que na fase de Pré-Teste (correlações 0,92 e 0,68, respectivamente). Este tipo de configuração confirma a existência de uma diferenciação entre as duas fases e os dois tipos de emoções. Além do mais, indica haver uma maior similaridade entre as duas emoções no Pós-Teste do que no Pré-Teste. É possível hipotetizar que a fase lúdica de intervenção no grupo Experimental e a repetição da tarefa de avaliação nos três grupos deva ter levado a criança ao estabelecimento de um paralelismo na compreensão das estratégias de regulação da tristeza e da raiva. Observa-se também uma maior proximidade entre Pré e Pós-Teste na emoção Raiva do que na emoção Tristeza (correlações 0,89 e 0,56, respectivamente).

Uma inspeção da projeção considerando como as variáveis externas se localizam no espaço SSA composto pelas variáveis de conteúdo confirma o efeito positivo da intervenção na elaboração de estratégias de RE. A localização do grupo experimental na região Pós-Teste e dos dois grupos de controle na região Pré-Teste reflete a maior elaboração de estratégias de RE no grupo Experimental. De fato, os escores no Pós-Teste são sempre mais altos do que no Pré-Teste (independentemente do grupo) e as diferenças são muito mais acentuadas no grupo Experimental (Raiva 4,8 e Tristeza 4,3) do que no grupo de Controle 1 (Raiva 1,0 e Tristeza 1,5) e no grupo de Controle 2 (Raiva 0,3 e Tristeza 1,9). É interessante observar também que a proximidade entre os dois grupos de controle na projeção indica uma similaridade entre estes dois grupos e uma dis-similaridade do grupo experimental e, conseqüentemente, confirma o efeito positivo da intervenção operada nas crianças do grupo experimental.

\section{Discussão}

Como este estudo mostrou, o brinquedo traduz-se em veículo rico a ser utilizado com funções mais potencializadoras para crianças em situação de hospitalização. 
Com este instrumento, pôde-se obter resultados diferentes daqueles observados por Harris e Lipian (1989), quando as crianças mantinham um pessimismo em relação a usar estratégias para mudar seu estado anímico frente à situação de hospitalização. Logicamente, não se pretende afirmar que com uma única sessão lúdica, as crianças estejam prontas para elaborar as situações em que suas emoções são obviamente mobilizadas, mas mostra um caminho a se conseguir determinados avanços, seja em hospitais privados ou públicos, com material que pode ser disponibilizado facilmente, bastando para isto, profissionais competentes.

Na emergência da situação de hospitalização infantil, notase normalmente um certo despreparo em se lidar com os sentimentos que são suscitados pela própria situação, de dor, sofrimento, agressividade, o que na maioria das vezes leva a uma inadequabilidade nas formas de se tratar a criança em questão, para auxiliá-la a vivenciar esta situação de forma mais satisfatória e assim contribuir para uma promoção de saúde e de uma melhoria na evolução do quadro clínico dessa.

Neste contexto, aparecem os recursos lúdicos no hospital sendo utilizados muitas vezes apenas para funções de distração e de proporcionar conforto, visto que, o brinquedo quando trazido de casa, por exemplo, torna-se uma referência da família, do contexto do qual a criança viu-se obrigada a se separar. Contudo, este estudo vem mostrar que pode se contribuir mais efetivamente para a promoção da saúde, tomando esta como "biopsicossocial". As ferramentas lúdicas vêm auxiliar nas esferas diagnóstica e intervencionista no exercício do trabalho com crianças, pois através destes recursos, a criança não somente expressa as formas que estabelece em lidar com emoções (estratégias de RE), como também, através desses e com o auxílio de alguém capacitado para sugerir e clarificar estratégias, esta criança consegue elaborar os diversos significados dos conteúdos que emergem na situação de hospitalização e consegue obter melhorias na forma de lidar com suas emoções.

Isso posto, poderíamos fazer então uma pergunta: qual o objetivo principal da ludoterapia no hospital? O de "cura", no sentido de "tratar" um sintoma psíquico que emerge conjuntamente com o sintoma orgânico na hospitalização infantil? Esta pesquisa tem o objetivo de mostrar que não somente isso, mas o brinquedo tem um papel muito mais abrangente, que se estenderia não só a contribuir para um decurso satisfatório do desenvolvimento infantil, mas também em proporcionar "saltos qualitativos" nesse desenvolvimento, oportunizando essa criança a apreender novos conteúdos que aparecem nesta situação e a construção de significados importantes na concepção de si e de suas emoções que fazem parte de suas experiências dentro e fora do hospital. E esses "saltos qualitativos" podem ser alcançados mesmo na situação de hospitalização.

Os dados do estudo demonstram que a hospitalização pode não se configurar em "quebra", em "ruptura" no processo de desenvolvimento de uma criança, como apontam muitos autores (Campos, 1995; Chiattone, 1988; Lindquist, 1993), mas pelo contrário, pode ser integrada à sua vida, como parte dela, experienciada, elaborada e produzindo a construção de novos significados que vão então ser úteis não só para o entendimento da situação específica, mas significados que serão estendidos para a uma compreensão maior, da sua vida, e suas relações com o seu meio.

Trabalhar com recursos lúdicos, como ficou claro, significa tentar encontrar no brinquedo livre (histórias semiestruturadas) como ela lida com as emoções suscitadas pela situação de hospitalização, utilizando-se dos significados que ela traz consigo, construídos nas suas relações com os pais, com a família, amigos, escola, etc. Somente a partir desta avaliação, é que se pode, através do brinquedo dirigido, (como no estudo em questão, família de fantoches e fantoches que representavam a criança e a equipe hospitalar), específico para trabalhar com determinados conteúdos, auxiliá-la no sentido de sintetizar, integrar estes significados para uma elaboração de si, na construção da identidade desta criança, de que estratégias utiliza para lidar com suas emoções, do significado de suas relações com amigos, parentes, escola, e como trabalhar com situações novas e inesperadas, como o é a hospitalização. E assim como a hospitalização, haverá ainda outras, que não necessariamente estejam ligadas à incidência de uma patologia.

Neste sentido, é necessário entender que as estratégias utilizadas para controle da emoção, culturalmente têm sido constituídas para compreender e agir diante das várias situações. Este entendimento se configura extremamente importante para que se possa delinear um plano de intervenção. E este caminho é dado pela criança, e não pelo psicólogo. É preciso então entender que as diferenças culturais, as características de uma determinada comunidade em que uma criança está inserida, são constitutivas no processo de construção do eu desta criança. Como apontaram Vikan e Dias (1996), as crianças brasileiras utilizam em sua maioria, as estratégias de Interação Social e Brincadeira, como formas de lidar com suas emoções. Provavelmente isto se deve ao fato de crianças no Brasil, e principalmente nos extratos menos favorecidos da sociedade, viverem e se constituírem muito mais coletivamente que individualmente, o que pode então se traduzir como justificativa à utilização destas estratégias referidas.

Esta visão nos possibilita ainda refletir sobre outras questões referentes à hospitalização infantil: tendo sido 
observado que as crianças brasileiras utilizam em sua maioria a Brincadeira e a Interação Social como estratégias para controle de suas emoções, o que dizer da situação de hospitalização que não lhes possibilita acesso a nenhuma das duas? Não seria este fato um fator a mais para a regressão, apatia, angústia vivenciadas por estas crianças?

Este estudo preocupou-se principalmente em mostrar o poder dos recursos lúdicos principalmente como forma de possibilitar, através desses, um acesso a uma das formas de se cessar raiva e tristeza e ainda veicular uma possibilidade de melhorias nas estratégias estabelecidas.

Finalizando, é preciso que se tenha em mente que o compromisso na construção de conhecimentos em psicologia preocupado em uma promoção de saúde a crianças, é muito maior que o do "tratamento" do choro, agressividade, apatia, entre outros "sintomas" comuns à hospitalização. Este compromisso traduz-se em tentar auxiliar esta criança a atravessar a situação de hospitalização ou de doença com mais benefícios que malefícios, de tentar fazer com que esta situação não seja somente de dor e sofrimento, mas que seja também uma situação rica em conteúdos a serem significados e ressignificados em contribuição para a sua saúde, no sentido amplo do termo, bio-psico-sócio-histórico-cultural. Afinal, entendese que promover saúde não se restringe à ordem curativa e reduzida ao tempo em que se permanece na instituição hospitalar. É preciso que se pense no momento posterior, na volta para casa, para que o trabalho que tenha sido desenvolvido no hospital seja útil também para o decorrer da vida desta criança.

\section{Referências}

Altshuler, J. A. \& Ruble, D. N. (1989). Developmental changes in children's awareness of strategies for coping with uncontrollable stress. Child Development, 60, 1337-1349.

Amar, R. \& Levy, S. (1995). External variables in WSSA1: Prediction from a structural configuration. Em J. J. Hox, P. Swanborn \& G. J. Mellemberg (Orgs.), Facet Theory: Theory and content (pp. 187-196). Zeist: SETOS.

Band, E. B. \& Weisz, J. R. (1988). How to feel better when it feels bad: Children's perspectives on coping with everyday stress. Developmental Psychology, 24, 246-253.

Bayley, K. D. (1974). Interpreting smallest space analysis. Sociological Methods \& Research, 3, 3-29.

Borg, I. \& Lingoes, J. C. (1987). Multidimensional similarity structure analysis. New York: Springer.

Bruner, J. S. (1976). Nature and uses of immaturity. Em J. S. Bruner, A. Jolly \& K. Sylvia (Orgs.), Play: Its role in development and evolution (pp. 28-64). New York: Penguin Books.

Bruner, J. S. (1978). O processo de educação. São Paulo: Nacional.

Campos, T. C. P. (1995). Psicologia hospitalar: A atuação do psicólogo em hospitais. São Paulo: EPU.

Chiattone, H. B. C. (1988). A criança e a hospitalização. Em V. A. AngeramiCamon (Org.), Psicologia hospitalar (pp. 95-102). São Paulo: Pioneira.
Chiattone, H. B. C. (1996). A criança e a morte. Em V. A. Angerami-Camon (Org.), E a psicologia entrou no hospital... (pp. 69-146). São Paulo: Pioneira.

Cohen, E. H. \& Amar, R. (1999). External variables in SSA and unfolding techniques: A comparison. Em R. Meyer Schweizer, D. Hänzi, B. Jann, E. Peier-Kläntschi \& H. J. Schweizer-Meyer (Orgs.), Facet theory: Design and analysis (pp. 259-279). Bern: FTA - Facet Theory Association (c/o Institut für Soziologie, Universität Bern).

Dias, M. G., Vikan, A. \& Gravas, S. (2000). Tentativa de crianças em lidar com as emoções de raiva e tristeza. Estudos de Psicologia, 5, 49-70.

Erikson, E. (1978). Infância e sociedade. Rio de Janeiro: Zahar. (Original publicado em 1959)

Freud, S. (1981). Mas alla del principio del placer. Madrid: Biblioteca Nueva. (Original publicado em 1920)

Freud, S. (1929/1981). El malestar en la cultura. Madrid: Biblioteca Nueva. (Original publicado em 1929)

Guttman, L. (1968). A general nonmetric technique for finding the smallest co-ordinate space for a configuration. Psychometrika, 33, 469-506.

Harris, P. L. (1983). Children's understanding of the link between situation and emotion. Journal of Experimental Child Psychologies, 36, 490-509.

Harris, P. L. (1996). Criança e emoção: O desenvolvimento da compreensão psicológica. São Paulo: Martins Fontes.

Harris, P. L., Guz, G. R., Lipian, M. S., \& Man-Shu, Z. (1985). Insight into the time-course of emotion among Western and Chinese children. Child Development, 56, 972-988.

Harris, P. L. \& Lipian, M. S. (1989). Understanding emotion and experiencing emotion. Em P. L. Harris \& C. Saari (Orgs.), Children's understanding of emotion (pp. 241-258). New York: Cambridge University Press.

Harris, P., Olthof, T. \& Terwogt, M. M. (1981). Children's knowledge of emotion. Journal of Child Psychiatry and Psychology, 22, 247-261.

Kenealy (1989). Children's strategies for coping with depression. Behavioral Research and Therapy, 27, 27-34.

Kohlberg, L. (1969). Stage and sequence: The cognitive-developmental approach to socialization. Em D. A. Goslin (Org.), Handbook of socialization theory and research (pp. 134-162). Chicago: Rand McNally College.

Langley, M. B. (1985). Selecting, adapting, and applying toys as learning tools for handicapped children. Topics in early childhood special education, 5, 131-148.

Latham, H. C., Heckel, R. V., Hebert, L. J. \& Bennett, E. (1977). General nursing care of the hospitalized child. Em H. C. Latham, R. V. Heckel, L. J. Hebert \& E. Bennett (Orgs.), Pediatric nursing (pp. 413-431). Saint Louis: Mosby.

Lindquist, I. (1993). A criança no hospital. São Paulo: Página Aberta

Lingoes, J. C. (1968). The multivariate analysis of qualitative data. Multivariate Behavioral Research, 3, 61-94.

Lyra, M. C. D .P., Roazzi, A. \& Cohen, E. (2001, Julho). A facet approach to the study of mothers', fathers' and pediatricians' conceptualisation on communication development in early infancy. Trabalho apresentado na $8^{\text {th }}$ Facet Theory Conference, Prague, República Checa.

Maldonado, M. T. (1989). Maternidade e paternidade. Petrópolis, RJ: Vozes.

McCoy, C .L. \& Masters, J. C. (1985). The development of children's strategies for the social control of emotion. Child Development, 56, 1214-1222.

Mello Filho, J. (1992). Psicossomática boje. Porto Alegre: Artes Médicas.

Piaget, J. (1975). A formação do símbolo na criança. Rio de Janeiro: Zahar.

Roazzi, A. (1995). Categorização, formação de conceitos e processos de construção de mundo: Procedimento de classificações múltiplas para o estudo de sistemas conceituais e sua forma de análise através de métodos de análise multidimensionais. Cadernos de Psicologia, 1, 127.

Rubin, K. H. \& Howe, N. (1985). Toys and play behaviour: An overview. Topics in Early Childhood Special Education, 5, 1-9. 
Saarni, C. (1989). Children's understanding of strategic control of emotional expression in social transaction. Em P. L. Harris \& C. Saarni (Orgs.), Children's understanding of emotion (pp. 181-208). New York: Cambridge University Press.

Taylor, D. A. \& Harris P. L. (1983). Knowledge of the link between emotion and memory among normal and maladjusted boys. Developmental Psychology, 19, 832-838.

Vieira, T. (1994). Aspectos motivacionais e cognitivos do uso de objetos em jogos de faz-de-conta. Psicologia Teoria e Pesquisa, 10, 22-27.

Vikan, A. \& Dias, M. G. (1996) Estratégias para o controle de emoções: Um estudo transcultural entre crianças. Arquivos Brasileiros de Psicologia, 48, $80-95$.

Vygotsky, L. S. (1994). O papel do brinquedo no desenvolvimento. Em M. Cole, V. J. Steiner, S. Scribner \& E. Souberman (Orgs.), A formação social da mente (pp. 121-138). São Paulo: Martins Fontes.
Winnicott, D. W. (1978). Pediatria e Psicanálise. Rio de Janeiro: Francisco Alves.

Young, F. W. (1987). Multidimensional scaling: History, theory and applications. Hillsdale, N.J.: Erlbaum.

Sobre os autores

Sâmela Soraya Gomes de Oliveira é Mestre em Psicologia Cognitiva pela Universidade Federal de Pernambuco.

Maria da Graça Bompastor Borges Dias é Doutora pela Universidade de Oxford, Inglaterra. É Professora do Programa de Pós-graduação em Psicologia da Universidade Federal de Pernambuco. Antonio Roazzi é Doutor pela Universidade de Oxford, Inglaterra. É Professor do Programa de Pós-graduação em Psicologia da Universidade Federal de Pernambuco. 


\section{MESTRADO E DOUTORADO EM PSICOLOGIA DO DESENVOLVIMENTO}

2003

Sevo

e você é graduado em Psicologia, tem um bom domínio da língua inglesa e deseja se preparar para ser um pesquisador, professor universitário, ou mesmo um profissional de alta qualificação, o Programa de Pós-Graduação em Psicologia do Desenvolvimento da Universidade Federal do Rio Grande do Sulé o local que você procura. Desfrute de um ambiente acadêmico estimulante, onde alunos e professores convivem diariamente, com dedicação integral ao estudo e à pesquisa. Escreva-nos pedindo maiores informações.

INFORMAÇÕES E INSCRIÇÃO

\section{UFRGS}

UNIVERSIDADE FEDERAL DO RIO GRANDE DO SUL

Instituto de Psicologia

PROGRAMA DE PÓS-GRADUAÇÃO EM PSICOLOGIA DO DESENVOLVIMENTO

Secretaria do PPG em Psicologia do Desenvolvimento - UFRGS

Rua Ramiro Barcelos, 2600 Sala 110 Campus da Saúde

90035-003 Porto Alegre RS Brasil

Fone: (51) 33165246 Fax: (51) 33309507

http://urso.psico.ufrgs.br/ppg

http://www.psicologia.ufrgs.br/pos_psico 